\title{
Processo decisório do aborto provocado: vivência de mulheres
}

I 1 Danyelle Leonette Araújo dos Santos, ${ }^{2}$ Rosineide Santana de Brito I

Resumo: Pesquisa interpretativa, em abordagem qualitativa, cujo objetivo foi analisar a vivência de mulheres no processo decisório do aborto provocado. Para tanto, foram entrevistadas 19 mulheres internadas em situação de aborto, no período de março a agosto de 2013, em uma maternidade-escola, situada em Natal, Rio Grande do Norte, Brasil. A análise das narrativas ocorreu com base nos referenciais teóricometodológicos da Teoria Fundamentada nos Dados e do Interacionismo Simbólico. Os resultados revelaram que as mulheres, ao suspeitarem da gravidez, realizaram diversos exames diagnósticos para confirmá-la. Tal confirmação as levou a vivenciar sentimentos negativos, relacionados ao reconhecimento do aborto como única alternativa possível. Dentre os principais motivos referidos por elas para interromperem a gravidez destacaram-se as dificuldades financeiras e o tipo de relacionamento amoroso. Espera-se que os dados obtidos nesta pesquisa possam ampliar as discussões sobre o fenômeno do aborto provocado, minimizando o estigma social imposto àquelas que o realizam.

> Palavras-chave: Aborto induzido; Saúde da Mulher; Saúde Pública.

\author{
1 Universidade Federal \\ do Rio Grande do Norte, \\ Departamento de Enfermagem. \\ Natal-RN, Brasil. Endereço \\ eletrônico: danyleonette@ \\ gmail.com \\ ${ }^{2}$ Universidade Federal \\ do Rio Grande do Norte, \\ Departamento de Enfermagem. \\ Natal-RN, Brasil. Endereço \\ eletrônico: rosineide@ufrnet.br
}

Recebido em: 13/11/2013

Aprovado em: 28/09/2014 
A prática do aborto voluntário é reconhecida oficialmente como grave problema de saúde pública desde a década de 1990, quando foram realizados, pela Organização das Nações Unidas (ONU), fóruns no intuito de discutir os direitos das mulheres como direitos humanos. Dentre tais eventos, a Conferência Internacional de População e Desenvolvimento (1994) e a IV Conferência Mundial sobre a Mulher (1995), realizadas, respectivamente no Cairo e em Pequim, se destacaram por requererem dos países signatários atenção especial ao aborto, solicitando, inclusive, revisão das leis proibitivas a esse evento. Tal solicitação tinha o propósito de minimizar os agravos à saúde feminina decorrentes da realização desse ato em condições precárias (ONU, 1994; 1995).

Embora o Estado brasileiro tenha participado das referidas conferências, poucos foram os avanços nas questôes legais referentes ao aborto voluntário. Entretanto, as restriçōes jurídicas em torno desse evento não interferem na busca das mulheres por formas clandestinas para interromperem uma gravidez. De acordo com a Pesquisa Nacional de Aborto (PNA), desenvolvida nas regiōes urbanas do Brasil, uma em cada cinco mulheres, na faixa etária entre 18-39 anos, já realizou pelo menos um aborto. Contudo, esses dados não mostram o quantitativo de abortos cometidos por cada uma, o qual certamente é maior, haja vista a possibilidade de uma mulher recorrer a esse ato várias vezes ao longo de sua vida (DINIZ; MEDEIROS, 2010).

Sabe-se que as estatísticas oficiais relativas a essa prática, em geral, são obtidas por meio do número de internações hospitalares. Essa fonte, porém, não se apresenta fidedigna. Isso porque, ao buscarem por assistência pós-aborto, existe o receio das mulheres de serem presas caso confirmem no ambiente hospitalar a interrupção da gravidez. Ademais, questões de cunho moral e religioso tendem a fazê-las silenciar suas experiências abortivas por medo de julgamentos dos profissionais e, inclusive, das pessoas de seu convívio (REDE FEMINISTA DE SAÚDE, 2005; BRASIL, 2009).

Por tais razões, o itinerário abortivo apresenta-se como um percurso sigiloso, ao qual muitas mulheres se submetem em busca dos meios para efetivar a decisão de abortar. Segundo Diniz e Medeiros (2012), entende-se por itinerário abortivo a trajetória percorrida para concretização do aborto, dividida em etapas que se iniciam com a constatação do atraso menstrual e a suspeita da gravidez até os cuidados pós-aborto. 
Relativo ao que se pode denominar primeira etapa desse itinerário, é nessa fase que ocorre a descoberta da gravidez e a decisão por interrompê-la, estando tal período permeado de intensa subjetividade, relacionada aos contextos sociais vivenciados por cada mulher. Estudos revelam inúmeros fatores predisponentes para as mulheres decidirem pelo aborto, dentre os quais se destacam as dificuldades financeiras, o número de filhos nascidos vivos, o receio de interromper projetos profissionais, um relacionamento amoroso instável e a rejeição da gravidez pelo parceiro (PEREIRA et al., 2012; FUSCO; SILVA; ANDREONI, 2012).

Compreende-se, portanto, ser esse primeiro momento de desconfiança e comprovação do ciclo gestatório um período em que a mulher reflete sobre suas condições de vida, analisando-as para decidir pôr um fim à gestação, não sendo algo realizado de forma impulsiva como idealizado no senso comum. É importante frisar ser esse processo decisório permeado de dúvidas e temores, principalmente, pelos preceitos religiosos disseminados na sociedade ocidental, os quais recriminam a prática do aborto, considerando-a, segundo Aguirre (2006), uma desordem moral grave, pois, elimina deliberadamente a vida de um inocente.

Mediante o exposto, conhecer como é vivenciada a decisão abortiva e as interações estabelecidas pelas mulheres nessa etapa do itinerário do aborto apresenta fundamental relevância para ampliar o conhecimento acerca desse fenômeno. Ao compreender melhor esse contexto, acredita-se ser possível suscitar reflexões entre os profissionais de saúde atuantes na área obstétrica, visando à promoção de uma assistência pautada na integralidade, isenta de preconceitos e julgamentos morais.

Sendo assim, a presente investigação ${ }^{1}$ buscou analisar a vivência de mulheres no processo decisório do aborto provocado.

\section{Métodos}

A pesquisa interpretativa, em abordagem qualitativa, foi desenvolvida em uma maternidade-escola localizada em Natal, Rio Grande do Norte. A escolha por essa unidade hospitalar se deu por ela ser referência terciária do Sistema Único de Saúde no estado, contabilizando uma média de 300 procedimentos pós-aborto por mês.

O estudo contou com a participação de 19 mulheres internadas em decorrência de aborto, entrevistadas obedecendo critérios de inclusão pré-estabelecidos, como: ter idade igual ou superior a 18 anos; admitirem, livremente, a indução 
do aborto; apresentarem condiçōes emocionais e físicas favoráveis para responder aos questionamentos (consciência, sem efeitos de drogas anestésicas, ausência de sangramento abundante e dores), bem como estarem internadas em decorrência da prática abortiva. Diante disso, mulheres com idade inferior a 18 anos que não informaram sobre a indução do aborto ou não se encontravam em condições emocionais e físicas satisfatórias para serem entrevistadas foram excluídas do estudo.

A coleta de dados ocorreu no período de março a agosto de 2013, por meio de entrevista em profundidade. Para nortear essa etapa, utilizou-se um roteiro constituído por questôes sociodemográficas e gineco-obstétricas, bem como por uma questão norteadora, referente ao objeto de estudo: "A senhora poderia me contar como decidiu interromper a sua gravidez?". As narrativas foram gravadas e analisadas conforme os referenciais teórico-metodológicos da Teoria Fundamentada nos Dados, proposta por Strauss e Corbin (2008), e do Interacionismo Simbólico, segundo Blumer (1969).

Com base na Teoria Fundamentada, a construção desta se dá de forma indutiva, na medida em que os dados vão emergindo dos discursos (STRAUSS; CORBIN, 2008). Assim, o tratamento das informações ocorreu em três etapas inter-relacionadas: codificação aberta, axial e seletiva. Desse modo, na primeira fase, os dados passaram por um processo de microanálise, possibilitando o surgimento das primeiras categorias, suas dimensōes e propriedades. $\mathrm{Na}$ codificação axial, estabeleceram-se relações entre essas categorias e subcategorias, objetivando promover explicações mais claras sobre o fenômeno. Finalmente, na fase seletiva, as categorias foram integradas, resultando na definição de uma categoria central (STRAUSS; CORBIN, 2008).

Após a análise, originou-se a categoria "Decidindo sobre a interrupção da gravidez" e as subcategorias "Descobrindo a gravidez", "Expressando sentimentos envolvidos no processo de decisão do aborto" e "Referindo os motivos para interromper a gravidez".

Quanto à análise dos dados, esta se embasou nos fundamentos do Interacionismo Simbólico, que possui três pilares fundamentais. O primeiro consiste no fato de cada pessoa interagir em relação às coisas de acordo com o significado que atribuem a elas. Entende-se por "coisas" tudo o que cerca o indivíduo, sejam pessoas, objetos físicos, atividades dos outros ou mesmo situaçôes do dia a dia. O segundo pilar diz respeito ao surgimento dos significados, o que ocorre mediante a interação entre 
duas pessoas, enquanto o terceiro e último pilar refere-se à manipulação desses significados por meio de processo interpretativo (BLUMER, 1969).

Deste modo, o alvo do Interacionismo Simbólico é o significado, que se origina da interação e interpretação feita sobre determinado acontecimento. As ações individuais e coletivas são construídas mediante a interação do ser consigo mesmo, da negociação individual e da reação do outro. Assim, o entendimento de que o indivíduo interage dinamicamente com tudo ao seu redor permite compreender sua relação com o ambiente (BLUMER, 1969). Por assumir um caráter interpretativo, possibilitando compreender as atitudes das pessoas com base nos significados atribuídos por elas a determinado evento, bem como as relações estabelecidas com outrem, entendeu-se ser o uso desse referencial adequado para analisar o processo decisório do aborto.

Ressalta-se que este estudo obedeceu a todos os preceitos éticos presentes na Resolução no 196/96 do Conselho Nacional de Saúde, vigente à época de sua realização. Assim, obteve-se aprovação do Comitê de Ética em Pesquisa da Universidade Federal do Rio Grande do Norte, com parecer favorável no 218.209 e CAAE no 10332312.9.0000.5537, e também foram solicitadas às participantes a assinatura formal do Termo de Consentimento Livre e Esclarecido, bem como sua autorização para gravação de voz. Salienta-se não ter havido recusa de nenhuma mulher em participar da investigação, nem para gravar a entrevista.

\section{Resultados e discussão}

\section{Caracterizando as participantes do estudo}

A idade das participantes do estudo variou entre 20 e 44 anos, com predomínio da faixa etária entre 26 e 30 anos. Tratando-se da etnia, nove entrevistadas declararam-se pardas, oito brancas e uma negra. Oito informaram ser católicas, seis evangélicas, três não seguiam nenhuma religião, porém afirmaram acreditar em Deus e duas mencionaram não ter crenças religiosas. Quanto ao estado civil, a maioria declarou-se solteira, contudo, afirmou vivenciar um relacionamento amoroso estável.

Relativo ao grau de escolaridade, majoritariamente, as mulheres declararam ter ensino médio completo. Quanto à ocupação, a maioria inseria-se no mercado formal de trabalho, predominando as atividades no setor de serviços, como 
comércio. Concernente à renda familiar, considerando o salário mínimo equivalente a R\$ 678,00 (2013), observou-se predomínio de valores entre 1 e 3 salários mínimos.

Sobre os dados gineco-obstétricos, 13 mulheres tinham, pelo menos, um filho. Todas declararam fazer uso de algum contraceptivo, sendo os anticoncepcionais orais e injetáveis os mais citados. Referente aos abortos pregressos, nove já haviam experimentado essa situação e destas, sete revelaram ter induzido, anteriormente, um ou mais abortos. Tratando-se da gestação atual, a maior parte das entrevistadas estava com idade gestacional entre cinco e seis semanas na ocorrência do aborto. Para a interrupção da gravidez, o Cytotec ${ }^{\circledR}$ usado isoladamente foi o método abortivo mais referido. Ressalta-se que uma minoria ingeriu esse fármaco combinando-o com chás ou utilizou apenas um preparado de ervas (garrafada) associado a esforços físicos excessivos.

Os dados ora expostos corroboram resultados encontrados por outros autores, de mulheres de diferentes crenças religiosas, pardas, solteiras, trabalhadoras fora do âmbito doméstico, cujas idades inseriam-se no intervalo entre 18 e 29 anos, como aquelas que mais recorrem à prática abortiva, fazendo uso de Cytotec $^{\circledR}$ (DINIZ; MEDEIROS, 2010; 2012).

\section{Decidindo sobre a interrupção da gravidez Descobrindo a gravidez}

Observou-se que as mulheres, antes de constatarem a gravidez, passaram por um estágio de desconfiança, embasadas pela ocorrência de uma relação sexual desprotegida, seguida de atraso menstrual e mudanças corporais. Essas últimas apresentaram-se como essenciais para as participantes suspeitarem ou mesmo constatarem o estado de gravidez, situação ocorrida, especialmente, pela experiência em gestaçóes anteriores.

[...] apareceu muito enjoo e meus peitos tavam doendo. Aí eu já descobri logo [a gravidez]. Porque meu primeiro menino foi assim também. [...] Antes de fazer o teste [de gravidez] eu já tinha aquela certeza dentro de mim, só não queria aceitar. (E15)

[...] eu já comecei a passar mal, a sentir náuseas, enjoos, meus peitos rapidamente já começaram a doer, e eu já tenho duas filhas, né, conheço os sintomas. (E19)

$\mathrm{O}$ fato de a maioria das participantes já ter vivenciado anteriormente uma ou mais gestações as levou a ter certeza sobre sua condição diante dos sintomas específicos do período gestatório. Acredita-se que isso ocorreu devido ao estabelecimento de um processo mental capaz de promover comparações entre 
a situação atual e o passado, permitindo às mulheres resgatarem lembranças de gestações anteriores e as informações adquiridas nestas para confirmarem seus pressentimentos. Salienta-se que esse processo mental também se deu entre as primigestas, as quais, em geral, recorreram à vivência de pessoas próximas, objetivando comprovar ou refutar suas interpretaçóes quanto às mudanças já estabelecidas em seus corpos.

Para Marcon (1995), ao suspeitar da gravidez, a mulher estabelece uma consciência acerca da possibilidade de existência real daquela, tornando-se mais alerta às alterações corporais já evidenciadas. Nesse sentido, passa a buscar mecanismos de negação dos sintomas ou começa a se preparar para ter suas dúvidas confirmadas, podendo isso ocorrer a partir de conhecimentos adquiridos em experiências pregressas ou realização de exames diagnósticos.

Essa realidade foi identificada no presente estudo, pois, embora as entrevistadas tenham recorrido a suas vivências anteriores ou de terceiros para se perceberem gestantes, a maioria realizou exames laboratoriais, testes de gravidez vendidos em farmácia ou ambos, no intuito de constatarem sua condição.

Começou com tanto enjoo. [...] vomitei bastante. [...] Até o dia que eu realmente decidi fazer um exame de Beta-HCG pra ver o que era que tinha. (E16)

[...] eu fiz um exame de farmácia, aí deu positivo. Aí, eu não acreditei. Aí, eu peguei e fui fazer o beta[-HCG]. Aí fiz o beta, aí deu positivo também. (E17)

A realização de um exame diagnóstico apresenta-se como aspecto fundamental para traçar o limite entre a suspeita e a comprovação da gravidez. É a partir dessa confirmação que a mulher se conscientiza da existência de um ser em desenvolvimento dentro de si e começa a definir mentalmente os rumos da gestação. Contudo, essa certeza de estar grávida pode variar de acordo com o desejo de gestar um novo filho, realidade expressa no descrédito dado aos resultados dos exames, levando-as a realizarem outros para se conformarem com seu estado.

Nas narrativas, pode-se evidenciar que esse momento demarcou o início do processo decisório do aborto, fazendo emergir nas mulheres diversas reflexóes acerca dos prós e contras para darem continuidade a gestação. De acordo com a PNA, a realização de exames faz parte do itinerário do aborto ilegal, sendo utilizados vários meios diagnósticos: o exame beta-HCG, testes de farmácia e a ultrassonografia obstétrica. Esse último foi evidenciado como uma novidade no 
referido itinerário, pois além de ser mais invasivo, possibilita a visualização do embriāo ou feto (DINIZ; MEDEIROS, 2012).

Ao visualizar o embrião, acredita-se que a mulher deixa de concebê-lo como "algo" e passa a interpretar as imagens como as de "alguém” em processo de formação intrauterina, adquirindo, portanto, um significado maior para ela. Essa significação ocorre porque as imagens e as informaçōes fornecidas por esse exame fazem a gravidez tornar-se real e promovem a mulher ao patamar de mãe (CHAZAN, 2008).

Assim, a realização da ultrassonografia poderia ser um fator impeditivo na decisão do aborto. Entretanto, nos discursos de algumas entrevistadas, esse exame foi imperativo em seu processo decisório, relacionado, especialmente, por permitir conhecer a idade gestacional.

[...] eu fui fazer logo o exame de sangue, aí deu positivo. [...] Depois, eu bati uma ultra. [...] eu disse: "se tiver grandinho, eu não vou tirar!" Mas, só tinha uma pintinha, num tinha nada! [...] Tava tão pequenininho que eu num boto nem na cabeça que era uma vida [Silêncio]. Eu tive coragem porque tava pequenininho. (E8)

[...] eu fui fazer um exame de farmácia [...] daí deu positivo. Depois, eu fui fazer o exame de sangue e também deu positivo. Aí, eu fui fazer a ultra que deu que eu tava com quatro semanas. E, daí, eu pensei, repensei e decidi induzir o aborto. [...] Só que antes de fazer fui tirar uma outra ultra pra saber como é que tava e já tava com seis semanas, aí fiz. (E19)

Percebe-se que a ultrassonografia aparece como um exame complementar, não sendo aquele de escolha inicial para diagnóstico da gravidez. Tal situação possivelmente ocorre pela maior facilidade de acesso e menor custo dos outros exames, podendo também estar relacionada à sua finalidade no processo de decisão da prática abortiva. Por ser mais detalhado, informar precisamente a idade gestacional e o estágio de desenvolvimento do embrião, o exame ultrassonográfico atuou, no universo das entrevistadas, como decisivo para optarem pelo aborto. Ao tomarem conhecimento do pouco tempo de gestação e identificarem nas imagens produzidas pelo exame apenas uma "mancha" ou "pintinha", e não algo semelhante a uma pessoa, algumas participantes estabeleceram em seu imaginário a inexistência de vida e foram imbuídas de coragem para provocar o aborto.

No âmbito dessas considerações, pesquisa realizada por Motta (2012) evidenciou o tempo de gestação como algo ponderado pelas mulheres na prática abortiva, visto considerarem que o concepto passa a se constituir enquanto pessoa e adquire cada vez mais vida com o avançar da gravidez. Essa ideia foi 
correlacionada à permissividade do público feminino em realizar abortos ainda nas primeiras semanas de gravidez.

É importante destacar a complexidade dessa situação, pois, apesar de a maioria das entrevistadas não ter identificado o embrião como um indivíduo, já o percebe como um ser com vida. Por terem tal percepção, algumas participantes referiram não realizar o exame ultrassonográfico por medo de perderem a coragem de persistir no itinerário do aborto. Aquelas que o fizeram relataram sensações ao visualizar o embrião devido ao pensamento de interromper aquele ciclo.

\footnotetext{
[...] eu sabia que era só um mês [de gestação]. Nem quis bater a ultra antes, senão, ia escutar o coração, ver... E não ia ter coragem. (E2)

[...] tu vê aquela ultra e, por mais que seja só uma bolinha ali no meio daquela escuridão toda que você vê da ultrassonografia, pesa um pouco a consciência, por saber o que você vai fazer. É uma vida! [...] (E19)
}

Embora tenha sido identificado na pesquisa o exame de imagem como algo importante no processo de decisão do aborto, as declaraçôes acima o revelam como algo perturbador. Acredita-se que isso ocorra pelo fato desse exame possibilitar à mulher interagir de maneira mais concreta com algo de que, até então, ela só havia se dado conta pelas mudanças fisiológicas e resultados confirmatórios escritos em papéis. Assim, observar o embrião e escutar seus batimentos cardíacos tende a fazê-las reconhecer a presença de uma vida, despertando sensações complexas e um sentimento de pesar pela ideia da prática abortiva.

Para Chazan (2005), o uso de tecnologias no período da gravidez promove uma tomada de consciência quanto a real existência do feto. Este, por sua vez, ao ser percebido por seus movimentos, ausculta dos batimentos cardiofetais e imagens que se assemelham a um ser humano, adquire o status de pessoa. Desse modo, pensar nos exames ultrassonográficos como um meio capaz de antecipar a existência social do feto, acarreta concepções pró-natalistas, as quais reforçam o surgimento de laços afetivos entre mãe e "bebê". Sendo assim, acredita-se que a concepção do feto como pessoa tenha sido utilizado para embasar os discursos das entrevistadas, desencadeando um sentimento de aflição por vincularem o aborto ao assassinato de um indivíduo.

Analisando o processo de descoberta da gravidez à luz do Interacionismo Simbólico, constata-se que, ao receber essa notícia, a mulher interpreta tal situação considerando suas condições de vida. E, a partir disso, adota uma postura intrinsecamente associada ao significado por ela atribuído à ocorrência 
1302 de uma gestação não planejada. Este processo mental é permeado por um emaranhado de sentimentos, os quais emergem, sobretudo, quando não há o desejo de continuar grávida.

\section{Expressando sentimentos envolvidos no processo de decisão do aborto}

A descoberta de uma gravidez não planejada desperta sensações diversas nas mulheres, imbricadas na aceitação dessa circunstância em suas vidas. Nesse sentido, a maioria das participantes afirmou ter recebido a notícia de que estava grávida com tristeza e desespero.

\section{[...] quando eu vi o resultado, aí, eu só faltei morrer! Na mesma hora eu pensei: 'vou tomar remédio, não posso ter [filho] não!' E o meu desespero? [...] (E12) \\ [...] depois que eu fiz o exame de sangue, eu não tive coragem de ver [o resultado]. Aí, vim andando e pensando [...] Quando eu abro [o exame], no meio da rua, o mundo inteiro para. Aí é que começa o desespero. Positivo! [...] o seu mundo cai! (E16)}

A negação da gravidez, presente de maneira significativa nos relatos, revelou-se como principal motivador à vivência de sentimentos negativos, os quais surgiram desde a suspeita e permaneceram até a comprovação do estado gravídico. A angústia em torno dessa confirmação fez as entrevistadas protelarem a busca por exames confirmatórios ou mesmo adiarem o recebimento de seu resultado. Desse modo, acredita-se que essa atitude se ancora no receio de enfrentar a realidade de uma gestação não planejada, que requer uma tomada de decisão sobre o seu desfecho. Ademais, a ideia de morte, expressa em diversas narrativas, mostra o desespero sentido ao descobrirem a gestação, evidenciando o quanto esta era indesejada.

Corroborando estes dados, pesquisas identificaram maior presença de emoções negativas diante da descoberta da gravidez em mulheres que induziram aborto quando comparadas com aquelas cujo evento se deu de maneira espontânea. Dentre tais sentimentos prevaleceram o desespero, a preocupação, a tristeza e o medo (BERTOLANI; OLIVEIRA, 2010; BORSARI et al., 2013).

Entende-se que o surgimento dessas emoções ultrapassa o óbvio e encontra raízes na percepção social da maternidade, que não deve ser negada, visto ser algo tido como sagrado e inerente à essência feminina. Apesar de a modernidade ter possibilitado mudanças na forma tradicional de conceber o papel da mulher no âmbito social, a maternidade ainda permanece sendo uma marca identitária categórica do grupo feminino, sobretudo, pela relação com a fisiologia de seus corpos (RODRIGUES, 2008). 
Desse modo, é possível compreender a ambivalência emocional externada pelas participantes da investigação. $\mathrm{Na}$ medida em que não desejavam dar continuidade à gravidez, viam-se frustrando expectativas sociais e burlando valores morais adquiridos em sua socialização, os quais nem sempre pretendiam infringir. Esse conflito embasava-se na contradição de sentir, simultaneamente, felicidade e tristeza, principalmente, por estarem convictas da necessidade de interromper a gestação.

Eu fiquei feliz quando descobri que tava grávida. Feliz, mas que vinha um bocado de coisa pela frente. Uma carga grande, sabe? Em cima de mim. [...] Tinha que fazer isso [aborto]... [Respira profundamente] (E6)

Eu fiquei feliz e também fiquei triste quando soube que tava grávida. Por que eu já sabia que ia ser interrompida, desde o primeiro momento que eu engravidei, eu já sabia. (E9)

Apesar desse conflito de sentimentos não ter sido mencionado diretamente por todas as participantes, ele foi percebido de maneira velada na totalidade das falas. Segundo Pérez (2006), isto ocorre pela ambiguidade entre a vontade e o descontentamento em decidir pelo aborto, visto, geralmente, como única solução diante de uma gravidez, não necessariamente indesejada.

Considerando o fato de as entrevistadas estarem inseridas em camadas populares, ao pensarem no aborto, elas interagiram com seus valores e contexto social, que estigmatizam a prática abortiva, deixando-as tristes por reconhecerem o aborto como única possibilidade real. Nesse sentido, percebe-se o modo como padrôes culturais determinados pela sociedade as influenciaram em suas formas de pensar e sentir durante o processo de decisão do aborto, concordando, portanto, com um dos fundamentos do Interacionismo Simbólico.

De acordo com Heilborn et al. (2012), os contextos sociais influenciam sobremaneira o modo como são percorridas, por homens e mulheres, as trajetórias em busca da concretização do aborto. Assim, mulheres de camadas populares mantêm a gravidez em segredo e vivenciam um itinerário abortivo mais sinuoso, com momentos de hesitação, recorrendo a inúmeros métodos inseguros para interromper a gravidez, realidade oposta à daquelas inseridas na classe média da sociedade.

Esses mesmos padróes corroboraram para as participantes sentirem-se culpadas quando se descobriram gestantes, especialmente, por entenderem ter facilitado à ocorrência da gravidez. Esta facilitação relacionou-se a falhas em seu 
papel de responsável pela contracepção e planejamento familiar, sobretudo, pelo esquecimento do uso (ou não utilização) de métodos anticoncepcionais, como pílulas e injeções.

Eu já uso injeção há 12 anos e eu, há um tempo, parei de tomar [...] Eu sabia que existia a possibilidade de engravidar, só que [...] ninguém vai usar camisinha namorando sete anos. Porque é muito ruim usar. É desconfortável e incomoda muito. Aí, uso sempre injeção pra evitar essas situações. Mas, dessa vez, eu confiei demais. Foi culpa minha, né? (E9)

A culpa é toda minha! Porque eu não tomo anticoncepcional. [...] Eu uso só camisinha. Aí, acabou acontecendo isso de estourar. [...] Confiei demais. (E18)

As relações entre os gêneros, presentes na sociedade, impõem às mulheres a responsabilidade exclusiva pela contracepção, fazendo-as sentirem-se culpadas quando esta não é realizada a contento. Nas narrativas, o sentimento de culpa emergiu de maneira unânime, mesmo entre aquelas que faziam uso de contraceptivos masculinos, cuja participação do homem era imprescindível, revelando o quão arraigada encontra-se a segregação de papéis na esfera reprodutiva.

Essa assimetria dos gêneros vincula-se à ideia de fazer parte da essência feminina a maternidade e as questōes referentes à reprodução. Assim, a culpabilização das mulheres quando se deparam com uma gravidez indesejada se relaciona ao pensamento de caber a elas a responsabilidade única de prevenir tal acontecimento (SOUZA; PORTO; CARVALHO, 2013).

Tratando desse assunto, Silva et al. (2011, p.2421) evidenciaram em seu estudo que, apesar das inúmeras mudanças relativas à divisão de tarefas entre homens e mulheres no contexto privado, não se percebe, ainda, efetiva participação masculina no planejamento familiar. Essa realidade ocorre, inclusive, em virtude da exclusão feita pelas próprias companheiras, que preferem deixar o homem à margem dessa situação, responsabilizando-se integralmente por esse aspecto da vida do casal. Tal fato é tido pelos autores como uma "armadilha de gênero", visto reproduzir e reforçar as concepções hegemônicas dessa natureza.

Esse entendimento também foi evidenciado nos relatos das entrevistadas, que se culparam por não terem usado contraceptivos hormonais e terem confiado apenas em uma forma de contracepção, o preservativo masculino. Nas falas dessas participantes, o sentimento de culpa pareceu ainda maior, revelando o quanto elas se sentiam responsáveis pela gravidez e eximiam os homens desse contexto. 
Apesar de diferentes estudiosos mencionarem a dificuldade das mulheres em negociarem com os parceiros o seu uso de camisinha, atribuindo a isso o poder exercido por eles na relação afetivo-sexual (CARVALHO, 2009; SILVA et al., 2011), os dados da presente pesquisa mostraram existir certa repulsa feminina em utilizar o preservativo, especialmente, em relacionamentos duradouros. Nesses casos, pode haver problemas no processo de negociação, embora isso não tenha ficado explícito nos relatos. Seja por confiança no companheiro, diminuição do prazer sexual ou por considerarem incômodo o uso, algumas mulheres referiram não gostar desse método e, ao esquecerem o contraceptivo hormonal, arriscaramse a engravidar para não se indispor no relacionamento amoroso.

Desse modo, entende-se que, diante da descoberta da gestação, o sentimento de culpa se estabeleceu devido a um processo reflexivo da mulher acerca de seu contexto de vida, ressignificando seus conhecimentos sobre métodos contraceptivos e a aplicabilidade destes em suas ações para prevenir uma gravidez. Ao estabelecerem essa associação, as entrevistadas culpabilizaram-se por não os ter ponderado e se arriscado em uma relação sexual desprotegida.

Todas as emoções negativas, emergentes do conflito instalado diante do desejo de interromper o ciclo gestatório, guardam relação com a censura e os julgamentos morais em torno da prática abortiva. Assim, as participantes vivenciaram esse processo decisório de forma estressante e sofrida.

Foi estressante viu? Eu não dormia [...] por causa disso, aquela coisa estressante. (E3)

Eu achei que [abortar] ia ser o melhor pra mim. Mas, te digo... É muito difícil! [Pausa] [...] O povo pensa que a gente não sofre, mas a gente sofre. (E6)

Essas declarações reforçam o sofrimento existente na tomada de decisão de interromper a gravidez, revelando a interação estabelecida pela mulher consigo mesma em momentos reflexivos antecedentes à efetivação, de fato, do aborto. Apesar de a ideia de realizar tal ato ter surgido, para a maioria das entrevistadas, no mesmo instante em que se descobriram grávidas, destaca-se ter existido um tempo necessário - que variou entre elas-, de reflexão sobre essa conduta, ponderando todas as consequências de sua escolha.

É senso comum associar a prática abortiva a uma atitude isenta de aflição e sofrimento, idealizando a imagem daquela que realiza esse ato como alguém desprendida e livre de padrões morais. Contudo, os discursos revelaram a 
angústia como um dos sentimentos mais presentes nesse momento de decisão. Possivelmente, isso está relacionado ao fato de ser o primeiro instante em toda a trajetória do aborto em que há ruptura das regras morais, religiosas e legais, gerando ambiguidades e emoções controversas, conforme mencionado anteriormente.

Segundo Borsari (2012), o sofrimento é inerente à essência humana. Contudo, sua manifestação é condicionada à cultura, à história e ao próprio indivíduo, apresentando-se como algo subjetivo e relativo ao contexto de cada um. Sob essa ótica, é possível conceber que o misto de sentimentos identificado no processo decisório do aborto relaciona-se às particularidades de vida das mulheres, avaliadas em um processo mental promovendo interação delas com suas convicções e realidade social. É essa interpretação de seu universo privado a responsável por identificar os motivos relevantes e capazes de impulsionar a prática abortiva.

\section{Referindo os motivos para interromper a gravidez}

Os motivos relatados pelas entrevistadas para interromperem a gestação foram diversos e variaram de acordo com suas condiçôes financeiras e seus relacionamentos familiar e amoroso. Salienta-se o fato desses motivos estarem relacionados e dependerem da realidade vivenciada por cada mulher. Por isso, foi notória a presença de inúmeras razões para optarem pelo aborto, sobressaindo o aspecto econômico, especialmente, quando as entrevistadas já tinham filhos.

[...] Eu vivo com minhas filhas nas situações que dá pra viver [...] Eu tô desempregada, não tenho dinheiro pra nada! [...] Como é que eu vou ter mais um filho sem condição nenhuma? (E10)

[...] eu comecei a pensar: 'Nossa, com três filhos eu não vou poder dar a mesma qualidade de vida que eu dou pras minhas duas filhas' [...] eu fui pensando por aí. Fiquei pensando nisso [...] Então, eu optei fazer o aborto. (E19)

Observa-se o temor das participantes em ter sua situação econômica agravada com o aumento da prole. Assim, percebe-se nesses relatos uma relação entre condição econômica e o número de filhos, o que ocasionaria mais gastos e, por conseguinte, maiores dificuldades financeiras. Tal realidade se acentuava quando a mulher não tinha vínculo empregatício, sendo autônoma ou dependendo de terceiros. Corroborando esse fato, estudos mostram o fator financeiro e o receio em não conseguir manter as necessidades básicas do filho como motivos intimamente relacionados à decisão feminina de abortar (BORSARI, 2012; FUSCO; SILVA; ANDREONI, 2012). 
Contudo, a questão financeira não esteve presente apenas nos discursos de mulheres com filhos. Ela também ganhou destaque entre aquelas mais jovens, que ainda não haviam vivenciado uma gestação. Nesses casos, a dependência financeira dos pais foi um fator relevante, especialmente, pela não aceitação da gravidez pelos familiares e por não terem recursos próprios para criar uma criança.

Outro aspecto evidenciado diz respeito ao fato da gestação ser considerada um obstáculo na busca por trabalho entre as entrevistadas sem emprego fixo ou desempregadas. Aquelas já empregadas relataram medo de perder o cargo caso o empregador descobrisse a gestação e, por tal motivo, optaram pelo aborto.

Eu desempregada, como seria? Eu grávida pra procurar emprego? Pra cuidar do meu filho e ainda vindo outro? Como eu ia trabalhar? (E11)

Eu pensei no meu trabalho. Se ela [patroa] soubesse disso [gravidez] ia me botar pra fora. [...] E eu comecei faz 15 dias. Como é que eu vou dizer que tô grávida? (E15)

Constatou-se uma preocupação significativa das participantes em manter seus postos de trabalho, especialmente, quando se declararam as principais responsáveis pelo sustento da família. Esse fato possibilita compreender a urgência em solucionar o "problema" vivenciado, objetivando preservar o emprego e a manutenção do lar. Assim, percebe-se haver uma associação direta entre gravidez e ônus, não apenas financeiro, mas também de autonomia feminina. Isso porque a perda ou impossibilidade de obter renda faria as mulheres retornarem a uma posição de dependência da família ou do companheiro.

Dados similares foram encontrados na investigação de Borsari (2012), a qual identificou o trabalho, o fator econômico e a participação ativa na vida social como aspectos importantes capazes de desencadear a rejeição da gravidez pela mulher. Nesse sentido, a presença de empecilhos na vivência plena dos fatores supracitados pode levá-la a não desejar seu estado e impulsioná-la à prática abortiva.

Apesar de a questão econômica ter-se revelado preponderante nos discursos, as entrevistadas buscaram associá-la, em geral, a outros aspectos de suas vidas para explicarem ou se convencerem do aborto como melhor escolha. Entre as mulheres mais jovens, destacaram-se em suas falas os projetos profissionais, sobretudo o desejo de adentrar ou dar continuidade aos estudos em um curso superior, sendo fundamental para rejeitarem a ideia de ter um ou mais filhos.

Porque eu pretendo fazer um curso, uma faculdade, estudar mais. Quer dizer, ia atrasar meus planos. [...] No passado, eu deixei muita coisa pra trás, pra cuidar da minha filha. Então, agora, eu teria que fazer isso novamente [...] E eu não queria isso. (E9) 
Eu poderia ter que abdicar do trabalho ou da faculdade. Porque fazer os dois não daria. E eu também pensava na minha liberdade. [...] Eu não tenho o apoio da minha mãe pra cuidar do meu filho se eu precisar. Aí, essas coisas também foram pesando. [...] (E13)

Essas declarações reforçam as mudanças em torno dos papéis desempenhados pelos gêneros na sociedade moderna, onde a mulher tem valorizado a carreira profissional, postergando a maternidade para um momento julgado como mais apropriado. Entretanto, segundo Scavone (2001), apesar das transformaçōes sociais, a função de mãe ainda prevalece como aspecto de forte significado na cultura feminina, gerando dilemas entre aquelas que buscam conciliar a vida profissional com a família.

Tais dilemas puderam ser identificados nas narrativas, que revelaram uma concepção, ainda que velada, da perda de liberdade caso a gestação fosse levada a termo. O papel de mãe estaria em uma posição de evidência, exigindo dedicação integral e impossibilitando a mulher de desempenhar outras tarefas, como estudo e trabalho. Assim, a ideia de voltar-se para o âmbito privado, cuidando da prole e afazeres domésticos pareceu ser uma espécie de prisão que cessaria a ascensão na vida pública.

Além da dificuldade financeira e dos aspectos capazes de agravá-la - número de filhos, ausência de vínculo trabalhista e dependência financeira-, identificouse nas entrevistas o relacionamento amoroso como fator determinante e, muitas vezes, decisivo para o episódio do aborto. A variedade nos tipos de relação afetiva foi evidenciada de maneira expressiva na decisão por interromper a gravidez. É justamente o modo pelo qual essa relação é vivenciada que define a postura do parceiro diante de uma gravidez não planejada e a interpretação dessa atitude pela mulher. Nessa conjuntura, o receio do parceiro não assumir as responsabilidades paternas, a falta de apoio masculino e o não desejo de criar um filho sem apoio parental foram razões ressaltadas como determinantes para a indução do aborto.

Eu quero ser mãe, agora só com um companheiro do lado. [...] Um homem responsável, trabalhador, que dê assistência [...], que seja amigo. Entendeu? [...] Não sozinha. (E4)

[...] esse filho agora não era do pai da minha filha não. Por isso que eu quis tirar. Foi só um lance [...]. Foi só uma vez! Eu só quero ter outro filho de um homem que esteja morando comigo dentro de uma casa. Entendeu? (E17)

Nas declarações, percebe-se a instabilidade e a casualidade na relação amorosa como fatores determinantes no processo de decisão do aborto. Nesse tipo de 
relação, existe o medo nas mulheres de não serem apoiadas no cuidado com o filho, pois o homem tende a não sentir-se também responsável por aquela gestação, visto não existirem laços de afetividade e confiança voltados à parceira. Assim, as entrevistadas que vivenciavam relacionamentos casuais, de curta duração ou no qual o parceiro não era visto com o estereótipo adequado para assumir o posto de pai, consideraram mais esses aspectos em detrimento de outros motivos ou os ponderaram de maneira equivalente para decidir finalizar a gravidez.

Conforme Ramírez-Gálvez (2005), a magnitude e o tipo de relação afetiva vivenciada pelo casal são imperativos para surgir a vontade de ter um filho. Desse modo, ao ocorrer uma gestação inesperada, são levados em conta os projetos femininos e masculinos relativos à formação familiar, bem como o desejo de ambos estabelecerem vínculos um com o outro por toda a vida.

Porém, quando se trata de relacionamentos instáveis, o interesse em constituir uma família parece ser reduzido. Por essa razão, o receio de criar um filho sozinha apresentou-se de maneira expressiva nos relatos, mas não esteve atrelado, exclusivamente, aos custos com a criação, pois envolveu também aspectos da socialização da criança. Embora sejam plurais os modelos de conformação familiar na atualidade, a ideia de constituir uma família nuclear mostrou-se significativa no presente estudo, sendo revelada uma visão romântica acerca do enlace conjugal com o parceiro e da concepção de filhos. Para tanto, o homem deveria apresentar diversos atributos como companheirismo, solidariedade, provedoria e, sobretudo, paternidade responsável. Essa última característica foi constantemente ressaltada pelas entrevistadas como um adjetivo necessário para o bom desenvolvimento emocional da criança.

Constata-se serem inúmeros os fatores ponderados pelas mulheres em seu processo decisório para interromper uma gravidez, os quais são interpretados por elas promovendo uma ressignificação do ciclo gestatório, bem como da prática abortiva. Isso se torna relevante, pois as leva a internalizarem a ideia do aborto como única alternativa possível diante de uma gestação não planejada, mesmo contrariando suas convicções morais.

\section{Considerações finais}

Os resultados obtidos nesta investigação possibilitaram analisar o processo decisório do aborto provocado, que se apresentou como uma escolha dolorosa 
na vida reprodutiva das entrevistadas. Tal fato deveu-se, especialmente, ao significado atribuído por elas à gravidez e ao aborto, situação que sofreu influência dos valores morais inerentes em seu contexto social.

O fato das colaboradoras desta pesquisa terem baixo poder aquisitivo, estando inseridas em camadas populares, acarretou a presença de valores sociais e religiosos influenciando o modo como experienciaram o aborto. Assim, embora tenham mencionado, diversas vezes, discordar da prática abortiva, as participantes, diante de uma gravidez indesejada, interagiram consigo mesmas e com seus contextos de vida, estabelecendo um novo significado para o ato de abortar, o qual passou a ser compreendido como algo necessário. Por esse motivo, as concepçōes negativas em torno desse ato persistiram, ocasionando sentimentos diversos como angústia, desespero e culpa frente à descoberta da gravidez e decisão de interrompê-la. Desse modo, as informações presentes neste estudo mostram a decisão do aborto como algo complexo, dependente de inúmeros fatores sociais, econômicos e culturais capazes de fazer as mulheres experienciarem esse evento de várias maneiras.

Reconhecendo o aborto como um fenômeno social, este deve ser analisado com base nessa ótica, no intuito de evitar estereótipos. Ao compreender o fenômeno dessa forma, espera-se ser possível minimizar os preconceitos e julgamentos morais que as mulheres sofrem em seus contextos sociais e quando buscam por assistência pós-aborto. ${ }^{2}$

\section{Referências}

AGUIRRE, L.P. Aspectos religiosos do aborto induzido: Cadernos n. 5. São Paulo: Católicas pelo direito de decidir, 2006.

BERTOLANI, G.B.M.; OLIVEIRA, E.M. Mulheres em situação de abortamento: estudo de caso. Saúde Soc., v.19, n.2, p.286-301, 2010.

BORSARI, C.M.G. Aborto provocado: vivência e significado. Um estudo fundamentado na fenomenologia. 2012. 122p. Dissertação (Mestrado em Ciências) - Faculdade de Medicina da Universidade de São Paulo, São Paulo, 2012.

BORSARI, C.M.G. et al. Aborto provocado em mulheres da periferia da cidade de São Paulo: vivência e aspectos socioeconômicos. Rev. Bras. Ginecol. Obstet., v. 35, n.1, p. $27-$ 32, 2013.

BLUMER, H. Symbolic interactionism perspective and method. California: Prentice-Hall, 1969.

BRASIL. Ministério da Saúde. Secretaria de Ciência, Tecnologia e Insumos Estratégicos. Departamento de Ciência e Tecnologia. Aborto e saúde pública no Brasil: 20 anos. Brasília: 
Ministério da Saúde, 2009. 428p. Disponível em: <http://bvsms.saude.gov.br/bvs/ publicacoes/livro_aborto.pdf>. Acesso em: 01 nov. 2013.

CARVALHO, S.M. Mulheres jovens e o processo de aborto clandestino: uma abordagem sociológica. 2009. 174p. Tese (Doutorado) - Escola Nacional de Saúde Pública Sérgio Arouca, Fundação Oswaldo Cruz, Rio de Janeiro, 2009.

CHAZAN, L.K. 'É... tá grávida mesmo! E ele é lindo!' A construção de 'verdades' na ultrassonografia obstétrica. Hist. Cienc. saude-Manguinhos, v. 15, n. 1, p. 99-116, 2008.

. "Meio quilo de gente!" - Produção do prazer de ver e construção da pessoa fetal mediada pela ultra-sonografia: um estudo etnográfico em clínicas de imagem da cidade do Rio de Janeiro. 2005. 338p. Tese (Doutorado) - Instituto de Medicina Social, Universidade do Estado do Rio de Janeiro, Rio de Janeiro, 2009.

DINIZ, D.; MEDEIROS, M. Aborto no Brasil: uma pesquisa domiciliar com técnica de urna. Ciênc. Saúde Colet., v. 15, n. supl. 1, p. 959-966, 2010.

Itinerários e métodos do aborto ilegal em cinco capitais brasileiras. Ciênc. Saúde Colet., v. 17, n. 7, p. 1671-1681, 2012.

FUSCO, C.L.B.; SILVA, R.S.: ANDREONI, S. Unsafe abortion: social determinants and health inequities in a vulnerable population in São Paulo, Brazil. Cad. Saúde Pública, v.28, n.4, p.709-719, 2012.

HEILBORN, M.L. et al. Itinerários abortivos em contexto de clandestinidade na cidade do Rio de Janeiro, Brasil. Ciênc. Saúde Colet., v. 17, n. 7, p. 1699-1708, 2012.

MARCON, S.S. Vivenciando a gravidez: processos e subprocessos de uma Teoria Fundamentada nos Dados. Rev Latino-am Enfermagem, v. 3, n. 2, p. 165-179, 1995.

MOTTA, F.M. Não conta pra ninguém: o aborto segundo mulheres de uma comunidade popular urbana. In: AREND, S.M.F.; ASSIS, G.O.; MOTTA, F.M. (Org.). Aborto e contracepçôes: histórias que ninguém conta. Florianópolis (SC): Insular, 2012. p. 97-136.

ORGANIZAÇÃO DAS NAÇÕES UNIDAS. Declaração e Programa de Ação da Conferência Internacional de População e Desenvolvimento. Cairo, 1994. Documento ONU A/CONF.171/1. Disponível em: <http://www.un.org/popin/icpd/conference/ offeng/poa.html>. Acesso em: 11 nov. 2013.

. Declaração e Programa de Ação da Conferência Mundial sobre Mulheres. Pequim, 1995. Documento ONU A/CONF.177/20. Disponível em: <http://www.un.org/esa/ gopher-data/conf/fwcw/off/a--20.en>. Acesso em: 11 nov. 2013.

PEREIRA, V.N. et al. Abortamento induzido: vivência de mulheres baianas. Saúde Soc., v. 21, n. 4, p. 1.056-1.062, 2012.

PÉREZ, B.A.G. Aborto provocado: representaçôes sociais de mulheres. 2006. 137p. Dissertação (Mestrado em Enfermagem) - Escola de Enfermagem da Universidade Federal da Bahia, Salvador, 2006. 
RAMÍREZ-GÁLVEZ, M.C. Preeminências femininas e ausências masculinas no aborto voluntário. In: ÁVILA, M.B.; PORTELLA, A.P.; FERREIRA, V. Novas Legalidades e democratização da vida social: família sexualidade e aborto. Rio de Janeiro: Garamond, 2005. p. 241-251.

REDE FEMINISTA DE SAÚDE. Dossiê aborto: mortes preveníveis e evitáveis. Belo Horizonte: Rede Feminista de Saúde, 2005. 48p. Disponível em: <http://abenfo. redesindical.com.br/arqs/manuais/081.pdf>. Acesso em: 20 out. 2013.

RODRIGUES, G.C. O dilema da maternidade. São Paulo: Annablume, 2008. 284p.

SCAVONE, L. Maternidade: transformações na família e nas relações de gênero. Interface (Botucatu), v.5, n.8, p.47-60, 2001.

SILVA, R.M. et al. Planejamento familiar: significado para mulheres em idade reprodutiva. Ciênc. Saúde Colet., n. 16, v. 5, p. 2.415-2.424, 2011.

SOUZA, C.H.D.; PORTO R.M.; CARVALHO, D.R.G.S. Paradoxos da atenção ao aborto provocado: "urgências" e "emergências" em uma Maternidade Escola em Natal/RN. Bagoas, v. 7, n. 9, p. 43-69, 2013. Disponível em: <http://periodicos.ufrn.br/bagoas/article/ view/4655/3811>. Acesso em: 20 jul 2014.

STRAUSS, A.; CORBIN, J. Pesquisa qualitativa: técnicas e procedimentos para o desenvolvimento da teoria fundamentada. 2.ed. Porto Alegre: Artmed, 2008.

\section{Notas}

${ }^{1}$ Recorte da dissertação intitulada Trajetória de mulheres e a participação masculina no processo do aborto provocado. Programa de Pós-graduação em Enfermagem da Universidade Federal do Rio Grande do Norte, 2013.

${ }^{2}$ D.L.A. dos Santos participou da concepção e elaboração do projeto, coleta, análise e interpretação dos dados, bem como redação do artigo. R.S. de Brito participou da elaboração do projeto, análise e interpretação dos dados e revisão final do artigo. 


\section{Abstract}

\section{Decision of induced abortion: experience of}

women

This is an interpretive research, whit a qualitative approach whose objective was to analyze the experience of women in the decision of induced abortion. We interviewed 19 hospitalized women undergoing abortion in March-August 2013, in a maternity hospital, in the city of Natal, Rio Grande do Norte, Brazil. The discourse analysis was based on methodological references of Grounded Theory and Symbolic Interaction. Results revealed that when women suspect pregnancy, they underwent several diagnostic tests to confirm it. This confirmation made them to experience negative feelings, which were associated to the recognition of abortion as the only possible alternative. The main reasons cited by respondents to finalize the pregnancy were financial difficulties and the kind of loving relationship. It is expected that the results obtained in this research can broaden the discussion on the phenomenon of induced abortion, reducing the social stigma imposed on women who do it.

> Key words: abortion, induced; women's health; Public Health. 